suggestion $^{16}$ that it resembles halothane hepatitis has been denied. ${ }^{17}$ Liver problems have not been documented after isoflurane, but, none the less, four of 27 cases reported to a subcommittee of the Food and Drug Administration in the United States over four years could not be attributed to other factors.

The incidence of reports of hepatotoxicity related to enflurane or isoflurane has not increased in the United States despite these agents having almost supplanted halothane. If that experience is translated to Britain the incidence of liver failure due to enflurane is likely to be one case a year if all 3 million surgical patients given anaesthesia received enflurane. Early results from Oxford of comparative studies of enflurane or isoflurane in a population likely to develop hepatitis related to halothane show that neither agent results in any substantial changes in liver function values. ${ }^{18}$

What, then, should the anaesthetist do to protect his patient from the remote possibility of liver damage and himself from the threat of litigation? Are there now any absolute indications for the repeated use of halothane within six months? The only problem comes where inappropriate concern about the added cost of using enflurane or isoflurane (or failure to provide the means to deliver these agents) may force the anaesthetist to put the patient unnecessarily at risk. Surely it is reasonable for the added cost of more expensive agents to be borne by the health authorities rather than their having to join the medical insurers in paying potentially huge settlements for avoidable halothane hepatitis?

Halothane hepatitis is as rare as mortality related to anaesthesia itself, and it is avoidable given adequate equipment, records, and forethought. The revolution that resulted from the introduction of halothane is likely to be replaced by another-the use of the more expensive but less hazardous enflurane and isoflurane.

Colin E BlogG

Consultant Anaesthetist,

Nuffield Department of Anaesthetics,

Radcliffe Infirmary,

Oxford OX2 6HE

1 Neuberger J, Williams R. Halothane anaesthesia and liver damage. Br Med f 1984;289:1136-9.

2 Kenna JG, Neuberger J, Williams R. Enzyme-linked immunosorbent assay for detection of antibodies against halothane-altered hepatocyte antigens. F Immunol Methods 1984:75:3-14

Whitburn RH, Sumner E. Halothane hepatitis in an eleven-month child. Anaesthesia 1986; (in press)

4 Plummer JL, Wanwimolruk S, Jenner MA, Hall P de la M, Cousins MJ. Effects of cimetidine and ranitidine on halothane metabolism and hepatotoxicity in an animal model. Drug Metab Dispos 1984;12:106-10.

5 Lunam CA, Cousins MJ, Hall P de la $M$. Guinea-pig model of halothane-associated hepatotoxicity in the absence of enzyme induction and hypoxia. $\mathcal{F}$ Pharmacol $E x p$ Ther 1985;232:802-9.

6 Hoft RH, Bunker JP, Goodman HI, Gregory PB. Halothane hepatitis in three pairs of closely related women. $N$ Engl I Med 1981;304:1023-4.

7 Bittrich NM, Kane AV'R, Mosher RE. Methohexital and its effect on liver function tests. A comparative study. Anesthesiology 1963;24:81-90.

8 Dundee JW. Thiopentone as a factor in the production of liver dysfunction. $\mathrm{Br} \mathrm{J}$ Anaesth 1955;27:14-23.

9 Dundee JW, Fee JPH, Moore J, Mcllroy PDA, Wilson DB. Changes in serum enzyme levels following ketamine infusions. Anaesthesia 1980;35:12-6.

10 Schemel WH. Unexpected hepatic dysfunction found by multiple laboratory screening. Current Researches in Anaesthesia and Analgesia 1976;55:810-2.

11 Sear JW, Prys-Roberts C, Dye A. Hepatic function after anaesthesia for major vascular reconstructive surgery. A comparison of four anaesthetic techniques. Br $\mathcal{F}$ Anaesth 1983;55: $603-9$

12 Chase RE, Holaday DA, Fiserova-Bergerova V, Saidman LJ, Mack FE. The biotransformation of Ethrane in man. Anesthesiology 1971;35:262-7

13 Holaday DA, Fiserova-Bergerova V, Latto IP, Zumbiel MA. Resistance of isoflurane to biotransformation in man. Anesthesiology 1975;43:325-32.

14 Mazze RI, Calverley RK, Smith NT. Inorganic fluoride nephrotoxicity: prolonged enflurane and halothane anesthesia in volunteers. Anesthesiology 1977;46:265-71.

15 Corrall IM, Snowdon S, Foëx P, et al. Enflurane in clinical practice. In: Bennetts FE, ed. Selected proceedings of the sixth European congress of anaesthesiology. New York: Biomedical Information Corporation, 1983:77-95.

16 Lewis JH, Zimmerman HJ, Ishak KG, et al. Enflurane hepatotoxicity. A clinicopathologic study 24 cases. Ann Intern Med 1983;98:984-92.

17 Eger EI, Smuckler EA, Ferrell LD, et al. Is enflurane hepatotoxic? Anesth Analg 1986;65:21-30.

18 Trowell J, Peto R, Smith AC. Controlled trial of repeated halothane anaesthetics in patients with carcinoma of the uterine cervix treated with radium. Lancet 1975;i:821-4.

\title{
Obese deceivers?
}

Without doubt obese people owe their excess body weight to the consumption of food energy in excess of their expenditure, ' yet many studies of food intake by the obese have shown-paradoxically - that their energy intakes are not excessive. In addition, a multitude of largely anecdotal, but occasionally well documented, examples have been reported of individuals who maintain excessive weight despite caloric restriction. ${ }^{2}$ The paradox has led many workers to propose and seek for metabolic causes, either in lower basal metabolic rates or lower expenditure in activities. In recent years a biochemical basis has been postulated for this apparent metabolic efficiency, ${ }^{3}$ leading to considerable interest in thermogenesis induced by diet and to elegant studies of brown adipose tissue.

The study of energy balance with the precision needed to test these various hypotheses has to overcome two main difficulties: firstly, the measurement of energy expenditure in people leading a normal life, and, secondly, the measurement of food intake and its translation into nutrient intake, the major challenge to the quantitative study of human nutrition. ${ }^{4}$ The first of these problems seems to have been solved by using water double labelled with deuterium and oxygen-18 together with improved instruments for measuring isotope mass ratio. We now have a procedure for measuring energy expenditure in free living people that is both ethical and non-restrictive. ${ }^{5}$ The method provides a measure of carbon dioxide production, and thus provides data equivalent to those generated by well established indirect calorimetric procedures.

A recent study by Prentice and colleagues (12 April, p 983) attempted to tackle various elements of the energy balance paradox in a group of women who became obese during or after pregnancy and compared them with a group of lean women. Their conclusion was that in this type of obesity (and possibly other types of maturity onset obesity) the cause of the paradox lies in the underestimation of food intake by the individuals being studied. They found that the basal metabolic rates of the obese women were higher than those of the lean ones-in proportion to their lean body mass. Their 24 hour energy expenditures, measured by classic indirect calorimetry, were also higher, as were their energy expenditures in their normal life, as measured by the use of double labelled water. In both cases total energy expenditures were related to their increased body weight.

The recorded food intake of the obese people was, however, lower than that of the lean-and some $800 \mathrm{kcal}$ less than energy expenditure. The obese group had lost weight during the study but even when this was taken into account their intakes were less than their expenditures by at least 500 $\mathrm{kcal}$ a day. Since the authors could find no evidence of lower 
metabolic needs or energy sparing mechanisms they were left with only one other possibility: the underestimation of food intake. They concluded that the obese people must have been consuming an average of $530 \mathrm{kcal}$ a day more than the lean controls in order to sustain their obesity. The cause of the obesity must, therefore, be sought in the control of food intake and eating behaviour.

This raises several questions. Is the deception deliberate? In this study did the obese misread the scales when they weighed their food or did they "forget" to weigh and record some foods? The size of the postulated underestimation appears too great to countenance accidental omission-it is equivalent to nearly a third of all the food they did record. Apparently these obese women were unable to admit to the experimenters (and probably to themselves) their actual food intake. Furthermore, the data from the lean group also included one substantial underestimation of intake; it might be difficult to prove that the lean were more consistent than the obese.

The paper also adds to the growing evidence that energy expenditures in normal life are lower than the currently accepted estimates of energy requirements. ${ }^{6}$ Nutritionists will need to bear this in mind if obesity is not to become more common than it is. The central finding, however, is that this type of obese patient should no longer be able to claim inherently lower metabolic requirements. We should treat with scepticism all claims from obese patients that their dietary intakes are modest. In such people, possibly even more than in the lean ones, habitual intake is impossible to measure accurately, at least with existing techniques-a message that needs to be appreciated much more widely. The measurement of food intake is so crucial that it might be argued that research on these techniques is more important than other more prestigious topics.

\section{A T SOUTHGate}

Head,

Nutrition and Food Quality Division,

Agricultural and Food Research Council Food Research Institute, Norwich NR4 7UA 1 Garrow JS. Treat obesity seriously: a clinical manual. London: Churchill Livingstone, 1981.
2 Royal College of Physicians. Obesity. I R Coll Physicians Lond 1983;17:3-58.
3 James WPT, Trayhurn P. Thermogenesis and obesity. Br Med Bull 1981;37:43-8.
4 Stockley L. Changes in habitual intake during weighed inventory surveys and duplication diet
collections. A short review. Ecology of Food and Nutrition 1985;17:263-9.
5 Lifson N, McClintock R. Theory of the use of the turnover rates of body water for measuring
energy and material balance. I Theor Biol 1966;12:46-74.
6 Department of Health and Social Security. Recommended daily amounts of food energy and nutrients
for groups of people in the United Kingdom. London: HMSO, 1979. (Report on Health and Social Subjects No 15 .)

\section{Regular Review}

\section{Psoriasis}

\section{R H CHAMPION}

Psoriasis was last reviewed in the $B M \mathcal{F}$ five years ago, ${ }^{1}$ and, though no major breakthroughs have been made in our understanding or treatment of the disease, many small but useful advances have been made and have influenced clinical practice. The ramifications of the disease make it of interest to both scientists and clinicians and some 1500 papers have been written about psoriasis in these five years, including some good reviews and an excellent 600 page monograph. ${ }^{2-6}$ Psoriasis remains one of the most common skin complaints, affecting about $1 \cdot 5 \%$ of the population-or even up to $5 \%$ at some stage of their lives. ${ }^{7}$ Once patients have developed psoriasis only $40 \%$ have prolonged remissions on long followup. ${ }^{8}$ The severity may range from a minimal occasional cosmetic problem to a life threatening emergency.

The aetiology of psoriasis is multifactorial. Most of the clinical and pathological changes may be explained on the basis of the rapid turnover of the epidermis, but this does not immediately explain the other main ingredient of psoriasisinflammation. We have come a long way from the observations of Van Scott and Ekel in 1963 that there is 27 times the normal rate of mitosis in the epidermis. ${ }^{\text {Normal skin }}$ produces 1246 new cells $\mathrm{cm}^{2}$ a day from a total 27000 cells; but psoriatic skin produces 35000 new cells $\mathrm{cm}^{2}$ a day from $52000 .^{1011}$ To achieve this dramatic increase the cell cycle is reduced from 311 to 36 hours; the proliferative cell population is doubled; and the proportion of basal cells actually concerned in division is also roughly doubled.

What causes this overactivity of the epidermis is still a vexed question. A genetic factor is undisputed but variable, probably with polygenic inheritance. Our usual concept of a powerful genetic influence has to be stretched to accommodate a disease which may appear for the first time at the age of $108 .^{12}$ The genetic influence seems less important in patients whose psoriasis starts later in adult life. Other trigger factors include trauma (a useful model for studying the disease), infection, drugs (notably lithium, chloroquine, and rarely $\beta$ blockers), and rather more nebulously climate and hormonal factors, and perhaps even smoking. ${ }^{13}$ The contribution of psychological stress is disputed. Most clinicians would agree that stress may modify the course of the disease, though seldom to the extent that some patients are led to believe, and there is only meagre scientific evidence for this. ${ }^{614} 15$

The whole skin is potentially abnormal in patients with 